\title{
PELATIHAN PEMBUATAN WEB DENGAN PHP PADA SMP NEGERI 27 PALEMBANG
}

\author{
Baibul tujni1), Megawaty²) \\ 1) Program Studi Komputerisasi Akuntansi-Vokasi Universitas Bina Darma \\ 2)Program Studi Teknik Informatika Universitas Bina Darma \\ Jl. A. Yani No. 12 Plaju Kota Palembang Kode pos 30264 \\ Email : $\underline{\text { baibul@binadarma.ac.id }}{ }^{1}$, megawaty@binadarma.ac.id $^{2)}$
}

\begin{abstract}
ABSTRAK
Pelatihan pembuatan website dengan php yang dilakukan pada SMP Negeri 27 Palembang dikarenakan pada SMP tersebut dirasa belum optimal dalam pemanfaatan teknologi informasi yang ada oleh sebab itu maka pengabdian ini dilakukan. Adapun peserta dalam pengabdian ini adalah guru-guru SMP Negeri 27 Palembang. kegiatan dalam pengabdian ini adalah memberikan pelatihan dan pendampingan dalam pembuatan Website dengan menggunakan PHP kepada para siswa dan siswi di SMP Negeri 27 Palembang. Adapaun manfaat dari pelatihan ini adalah diharapkan dapat meningkatkan kemampuan para siswa SMPN 27 Palembang dalam membuat database dengan Xampp sebagai server, Untuk meningkatkan pengetahuan para guru SMP Negeri 27 Palembang tentang bagaimana cara memanfaatkan PHPMyAdmin dalam memanajemen Sistem Database. Pentingnya pelatihan ini bagi SMP Negeri 27 Palembang karena dengan melihat perkembangan zaman tentang teknologi yang canggih oleh sebab itu para tenaga pendidik (guru) dituntut untuk dapat menggunakan teknologi tersebut agar tidak ketinggalan dan memperoleh wawasan baru dalam penggunaan teknologi informasi .
\end{abstract}

Kata kunci : Pelatihan, Web, PHP

\section{PENDAHULUAN}

Sekolah Menengah Pertama (SMP) Negeri 27 Palembang adalah sekolah menengah pertama Negeri yang berlokasi di Jl. Rejung Sako Kenten No. 198 Palembang. ini baru berdiri pada tahun 2008 lalu, meskipun baru tapi perkembangannya terbilang sangat pesat. SMPN 27 Palembang pada saat di operasionalkan tahun 20 November 1984 lalu. Karena masih kurangnya keterampilan dan keahlian yang dimiliki oleh guru-guru pada jurusan RPL ini masih sangat terbatas, untuk itulah kami tim pengabdian masyarakat berkeinginan memberikan pelatihan bagaimana memanfaatkan aplikasi xampp PHP MyAdmin bagi siswa dan siswi dengan harapan mereka dapat mengenal apa itu PHP dan apa itu database, bagaimana cara merancang sebuah database dan bagaimana cara membuat program dengan php. Tujuan dari pengabdian ini adalah meningkatkan kemampuan dan keahlian para siswa dalam memanfaatkan Xampp dan PHP mySql dalam merancang dan membangun database yang dibutuhkan dalam mendukung aplikasi bisnis sistem informasi. Memenuhi unsur tri darma perguruan tinggi bagi dosen Universitas Bina Darma Palembang sedangkan mafaat dari pengabdian ini adalah meningkatkan kemampuan para siswa SMPN 27 Palembang dalam membuat database dengan Xampp sebagai server, Untuk meningkatkan pengetahuan para guru SMP Negeri 27 Palembang tentang bagaimana cara memanfaatkan PHP MyAdmin dalam memanajemen Sistem Database.

Materi pelatihan Rekayasa Perangkat Lunak yang diberikan ini berhubungan dengan cara memanfaatkan aplikasi Xampp sebagai server dan PHPMyAdmin sebagai tools database manajemen sistem. oleh karena itu dalam kegiatan pengabdian masyarakat ini kami selaku dosen universitas Bina Darma dituntut untuk dapat memberikan ilmu yang didapat sebagai salah satu penunjang tri darma perguruan tinggi yaitu dengan memberikan pelatihan pemanfaatan Xampp dan PHP MyAdmin Bagi siswa-siswa SMPN 27 Palembang. Dengan pelatihan ini, kami harapkan agar dapat meningkatkan keahlian dan pengetahuan para guru SMP Negeri 27 Palembang. Selatan dibidang Sofware khususnya pada mata jurusan rekayasa perangkat lunak.

\subsection{Landasan Teori}

1) PHP MyAdmin 
2) Menurut Alexander F.K Sibero (2011:376) phpMyAdmin adalah aplikasi web yang dibuat oleh phpmyadmin.net phpMyAdmin digunakan untuk administrasi database MySQL. Menurut Bunafit Nugroho (2008:13) phpMyAdmin adalah aplikasi berbasis web yang dibuat dari pemrograman PHP dan diramu dengan JavaScript. phpMyAdmin juga dapat disebut sebagau tools yang berguna untuk mengkases yang ada database MySQL Server dalam bentuk tampilan web. Dengan adanya phpMyAdmin semua pekerjaan menjadi lebih muda, karena tanpa harus mengerti perintah-perintah dasar SQL, kita sudah dapat memanajemen database dan data di dalamnya

3) Perancangan

Perancangan adalah suatu proses yang bertujuan untuk menganalisis, menilai memperbaiki dan menyusun suatu sistem, baik sistem fisik maupun non fisik yang optimum untuk waktu yang akan datang dengan memanfaatkan informasi yang ada. Perancangan suatu alat termasuk dalam metode teknik, dengan demikian langkah-langkah pembuatan perancangan akan mengikuti metode teknik. Merris Asimov menerangkan bahwa perancangan teknik adalah suatu aktivitas dengan maksud tertentu menuju kearah tujuan dari pemenuhan kebutuhan manusia, terutama yang dapat diterima oleh faktor teknologi peradaban kita. Dari definisi tersebut terdapat tiga hal yang harus diperhatikan dalam perancangan yaitu : 1) aktifitas dengan maksud tertentu, 2) sasaran pada pemenuhan kebutuhan manusia dan 3) berdasarkan pada pertimbangan teknologi.

4) Xampp

Menurut Bunafit Nugroho (2008 : 2) XAMPP adalah suatu bundel web server yang populer digunakan untuk coba-coba di Windows karena kemudahan instalasinya. Bundel program open source tersebut berisi antara lain server web Apache, interpreter PHP, dan basis data MySQL. Setelah menginstall XAMPP, kita bisa memulai pemrograman PHP di komputer sendiri maupun mencoba menginstall aplikasi -aplikasi web.

5) MySQL

Menurut Bunafit Nugroho (2008 : 29) MySQL merupakan database yang berbasis server. Anda bisa menggunakan Database MySQL. apabila memiliki izin hak akses didalamnya. Hal ini seperti halnya pada saat anda hendak menggunakan klien MySQL untuk masuk pada server MySQL. Keunggulan dari MySQL adalah :

1. Bersifat open source.

2. Sistem software-nya tidak memberatkan kerja server atau komputer karena dapat bekerja di background

\section{6) Pelatihan}

Pengertian Pelatihan dalam Manajemen Sumberdaya Manusia. Menurut Gomes (2003:197), pelatihan adalah setiap usaha untuk memperbaiki performansi pekerja pada suatu pekerjaan tertentu yang sedang menjadi tanggung jawabnya, atau satu pekerjaan yang ada kaitannya dengan pekerjaannya.

\section{7) Komputer}

Menurut Blissmer (dalam Susanto, 2009) mengatakan bahwa komputer adalah suatu alat elektronik yang mampu melakukan beberapa tugas seperti menerima input, memproses input tadi sesuai dengan programnya, menyimpan perintah-perintah dan hasil pengolahan, serta menyediakan output dalam bentuk informasi. Pendapat lainnya yang terdapat pada paper milik Susanto (2009) mengenai definisi dan pengertian dari komputer berasal dari pendapat yang dikemukakan oleh Sanders. Sanders (dalam Susanto, 2009) mengatakan bahwa komputer merupakan suatu sistem elektronik utk memanipulasi data yg cepat dan tepat serta dirancang dan diorganisasikan supaya secara otomatis menerima dan menyimpan data input, memprosesnya dan menghasilkan output dibawah pengawasan suatu langkah-langkah, instruksi2 program yg tersimpan di memori (stored program)

\section{METODE PELAKSANAAN PENGABDIAN}

\subsection{Materi yang diberikan}

Program Pelatihan Penggunaan bahasa pemrograman php untuk pembuatan website pada SMP 27 Palembang di Universitas Bina Darma ini akan dilaksanakan sebanyak 5 kali pertemuan dimulai tanggal 15 juni sampai dengan tanggal 17 juni 2017. Yang dilaksanakan dari jam 9.00 pagi s.d jam 16.00 sore Adapun waktu dan materi yang diberikan sebagai berikut : 
Table 1. Materi yang di berikan

\begin{tabular}{|l|l|l|}
\hline \multicolumn{1}{|c|}{ Materi } & \multicolumn{1}{|c|}{ Pembicara } & \multicolumn{1}{c|}{ Tempat Pelaksanaan } \\
\hline Instalasi Xampp & Baibul Tujni & Lab. Komputer Univ. Bina Darma \\
\hline Pengenalan Xampp & Megawaty & Lab. Komputer Univ. Bina Darma \\
\hline Pengenalan PHPMyAdmin & Baibul & Lab. Komputer Univ. Bina Darma \\
\hline Menjalankan Server & Baibul & Lab. Komputer Univ. Bina Darma \\
\hline Database MySQL & Megawaty & Lab. Komputer Univ. Bina Darma \\
\hline Tipe Data & Megawaty & Lab. Komputer Univ. Bina Darma \\
\hline DDL pada PHPMyAdmin & Baibul Tujni & Lab. Komputer Univ. Bina Darma \\
\hline DML pada PHPMyAdmin & Baibul Tujni & Lab. Komputer Univ. Bina Darma \\
\hline Membuat Laporan & Megawaty & Lab. Komputer Univ. Bina Darma \\
\hline Penutupan & $\begin{array}{l}\text { Megawaty, } \\
\text { Baibul Tujni }\end{array}$ & Lab. Komputer Univ. Bina Darma \\
\hline
\end{tabular}

\subsection{Metode Pelaksanaan}

Pada kegiatan ini, diuraikan rangkaian kegiatan pengabdian, adalah sebagai berikut :

\section{1) Lokasi Pelaksanaan}

Kegiatan pengabdian ini dilaksanakan bagi para siswa SMPN 27 Palembang yang berlokasi di Laboratorium Komputer Universitas Bina Darma Palembang yang beralamat Jl.A.Yani No.12 Plaju Palembang.

\section{2) Waktu Pelaksanaan}

Kegiatan Pelatihan ini akan dilaksanakan selama 3 hari, terhitung dari tanggal 15 Juni 2017 s.d. 17 juni 2017, dimulai dari jam 09.00 sampai dengan jam 16.00 .

3) Jadwal Pelaksanaan Kegiatan

Table 2. Jadwal Pelaksanaan Kegiatan

\begin{tabular}{|c|c|c|c|}
\hline \multirow[t]{2}{*}{ Nama Kegiatan } & \multicolumn{3}{|c|}{ Juni } \\
\hline & 15 juni 2017 & 16 juni 2017 & 17 juni 2017 \\
\hline \multicolumn{4}{|l|}{ Survey Lokasi } \\
\hline \multicolumn{4}{|l|}{ Persiapan Kegiatan } \\
\hline \multicolumn{4}{|l|}{$\begin{array}{l}\text { Persiapan Materi Yang akan } \\
\text { disampaikan kepada peserta } \\
\text { pelatihan }\end{array}$} \\
\hline \multicolumn{4}{|l|}{ PembagianTugas } \\
\hline \multicolumn{4}{|l|}{$\begin{array}{l}\text { Persiapan alat dan bahan } \\
\text { untuk pelatihan pengenalan } \\
\text { teknologi jaringan komputer }\end{array}$} \\
\hline $\begin{array}{l}\text { Acara kegiatan (penyampaian } \\
\text { materi dan pelatihan } \\
\text { pembuatan website dengan } \\
\text { bahasa pemrograman php) }\end{array}$ & & & \\
\hline
\end{tabular}

\section{HASIL DAN PEMBAHASAN}

Adapun hasil yang dicapai pada kegiatan pengabdian masyarakat yang telah dilaksanakan di laboratorium Komputer Universitas Bina Darma ini adalah dimana tim dosen Universitas Bina Darma telah memberikan pelatihan ilmu pengetahuan dibidang Rekayasa Perangkat Lunak dan MySQL yaitu cara memanfaatkan Aplikasi Xampp sebagai Server dan PHPMyadmin sebagai tools database manajemen sistem. Dimana kegiatan pengabdian masyarakat ini diberikan kepada siswa kelas 7 SMPN 27 Palembang. dari kegiatan pengabdian ini tim dosen Univeristas Bina Darma berharap guru-guru dapat lebih memahami dan menguasai ilmu dibidang Software Engineering. Berikut data hasil kegiatan pengabdian masyarakat kepada siswa SMP Negeri 27 Palembang. 


\subsection{Jadwal Pelaksanaan Acara Kegiatan}

Tabel dibawah ini menunjukkan jadwal kegiatan acara pelatihan yang diadakan di laboratorium komputer Universitas Bina Darma Palembang yang berlangsung selama 3 hari.

Table 4. Jadwal Acara kegiatan

\begin{tabular}{|c|l|l|l|l|l|}
\hline Pertemuan & \multicolumn{1}{|c|}{$\begin{array}{c}\text { Pelaksanaan/ } \\
\text { Materi }\end{array}$} & $\begin{array}{c}\text { Tanggal/ } \\
\text { Waktu }\end{array}$ & $\begin{array}{c}\text { Metode } \\
\text { Kegiatan }\end{array}$ & Pelaksana & \multicolumn{1}{|c|}{ Output } \\
\hline I & $\begin{array}{l}\text { Instalasi Xampp } \\
\text { Pengenalan Xampp } \\
\text { Pengenalan } \\
\text { PHPMyAdmin }\end{array}$ & $\begin{array}{l}15 / 06 / 2017 \\
\text { Jam 09.00- } \\
16.00 \mathrm{wib}\end{array}$ & $\begin{array}{l}\text { Praktek } \\
\text { diskusi }\end{array}$ & Megawaty & $\begin{array}{l}\text { Peningkatan pengetahuan } \\
\text { para siswa dan diharapkan } \\
\text { mampu dalam membuat } \\
\text { halaman utama SMPN 27 PLG }\end{array}$ \\
\hline II & $\begin{array}{l}\text { Menjalankan Server } \\
\text { Database MySQL } \\
\text { Tipe Data }\end{array}$ & $\begin{array}{l}16 / 06 / 2017 \\
\text { jam 09.00- } \\
16.00 \mathrm{wib}\end{array}$ & $\begin{array}{l}\text { Praktek } \\
\text { langsung }\end{array}$ & $\begin{array}{l}\text { Baibul } \\
\text { Tujni }\end{array}$ & $\begin{array}{l}\text { Para Siswa SMPN 27 PLG } \\
\text { diharapkan mampu membuat } \\
\text { koneksi untuk } \\
\text { menghubungkan program php } \\
\text { dengan database, menmbah } \\
\text { data dan menampilkan data }\end{array}$ \\
\hline III & $\begin{array}{l}\text { DDL dan } \\
\text { PHPMyadmin }\end{array}$ & $\begin{array}{l}17 / 06 / 2017 \\
\text { jam 09.00- } \\
16.00 \mathrm{wib}\end{array}$ & $\begin{array}{l}\text { Praktek } \\
\text { Tanya } \\
\text { jawab }\end{array}$ & Megawaty & $\begin{array}{l}\text { Para siswa SMPN 27 PLG } \\
\text { dapat mengubah data, } \\
\text { menghapus data, mencari } \\
\text { data. }\end{array}$ \\
& $\begin{array}{l}\text { PHPMyadmin } \\
\text { Pembuat Laporan }\end{array}$ & & & & \\
\hline
\end{tabular}

\section{KESIMPULAN}

Adapun kesimpulan dari kegiatan pengabdian masyarakat kepada para siswa kelas 7 SMPN 27 Palembang sebagai berikut ini :

1. Kegiatan pengabdian ini memberikan pengetahuan sekaligus peningkatan mutu siswa SMPN 27 Palembang tentang teknologi Rekayasa Perangkat Lunak.

2. Diharapkan dengan kegiatan pengabdian ini siswa SMPN 27 Palembang memiliki kemampuan dalam dan mentrasnferkan ilmu yang mereka dapat kepada siswa dan data membuat program.

3. Dengan kegiatan pengabdian ini diharapkan dapat membekali siswa SMPN 27 Palembang dengan ilmu yang tidak hanya bersifat teori akan tetapi juga ilmu yang bersifat praktikum.

\section{Saran}

Adapun saran yang dapat diberikan pada kegiatan pengabdian masyarakat ini adalah :

1. Kegiatan pengabdian masyarakat ini diharapkan dilakukan berkelanjutan secara bertahap pada setiap semester sehingga dapat meningkatkan mutu siswa dalam mengenal teknologi informasi Rekayasa Perangkat Lunak

2. Kegiatan pengabdian masyarakat ini sebaiknya diarahkan lebih banyak kepada ilmu praktikum karena mendorong pengetahuan siswa-siswi lebih terampil dalam mengelola atau membuat suatu teknologi.

\section{DAFTAR PUSTAKA}

Susanto. A.B. 2009. Reputation Driven Corporate Social Responsibility pendekatan strategic management dalam CSR. Esensi Erlangga Group. Jakarta

Sibero, Alexander F. K, 2011, Kitab Suci Web Programing,MediaKom, Yogyakarta.

Nugroho. Bunafit. 2008. Aplikasi Pemrograman Web Dinamis Dengan PHP dan MySQL,Gava Media, Yogyakarta.

Gomes, Faustino Cardoso., 2003, Manajemen Sumber Daya Manusia, Penerbit Andi, Yogyakarta.

Syaukani, M. 2005. Mengolah data pada Mysql server. Elex media komputindo. Jakarta 